\title{
Huge Ovarian Mass with Pregnancy: a Case Report from Rural India
}

\author{
Swaroop Neelam, Ekta Singh*, Kumari kalpana and Maya Singh \\ Department of Obstetrics and Gynaecology, Santosh Medical College, India
}

Submission: February 06, 2017; Published: March 07, 2017

*Corresponding author: Ekta Singh, Department of Obstetrics and Gynaecology, Santosh Medical College, Ghaziabad, India, Email: ektasinghlhmc@gmail.com

\section{Introduction}

The incidence of ovarian tumors in pregnancy is approximately 1 in 1000, of which 2-5\% tumors are malignant (1 in 12,50025,000 pregnancies) [1]. Among all the tumours diagnosed during pregnancy, the germ cell tumours reportedly the most prevalent, and epithelial ovarian tumour accounts for $20 \%$ of all ovarian malignancy epithelial ovarian cancers affects predominantly perimenopausal and post menopausal women [2]. Ovarian mucinous cystadenocarcinoma, a subtype of epithelial ovarian cancer, is rarely diagnosed during pregnancy in young women. Ultrasound scanning in pregnancy has lately become a routine. It has led to more frequent findings of the relatively asymptomatic adnexal masses [3]. In the absence of large prospective randomized trials and cohort studies, it is difficult to know how best to manage these patients. In dealing with a pregnant woman with ovarian cancer, one must consider the effects of the malignancy on the woman and the fetus and how the pregnancy itself can change the diagnostic procedures and therapy [4].

In spite of all the facility, large ovarian masses can be detected accidently in rural background as in this case, because of lack of awareness of routine antenatal checkups in pregnancy. Here we discuss a rare case of large mucinous cystadenocarcinoma with undiagnosed live pregnancy of 16 weeks in a 26 years old multi gravida.

\section{Case Report}

An unbooked rural woman G4P2L2A1 aged 26yrs presented herself in our outpatient department with chief complaints of 4 months amenorrhea along with progressively enlarging large abdominal lump for last five months and pain in abdomen for 2 days.

On examination her built was average, general condition was fair with normal vitals. Abdomen was distended with normal overlying skin. On palpation a non tender firm to hard consistency lump of about 32 weeks size of gravid uterus with restricted mobility was found. Lump was non ballot able with reachable Lower pole. A separate 16 wks size mass having firm consistency felt in left iliac fossa (Figure1). Per speculum examination did not revealed any cervical or vaginal abnormality.

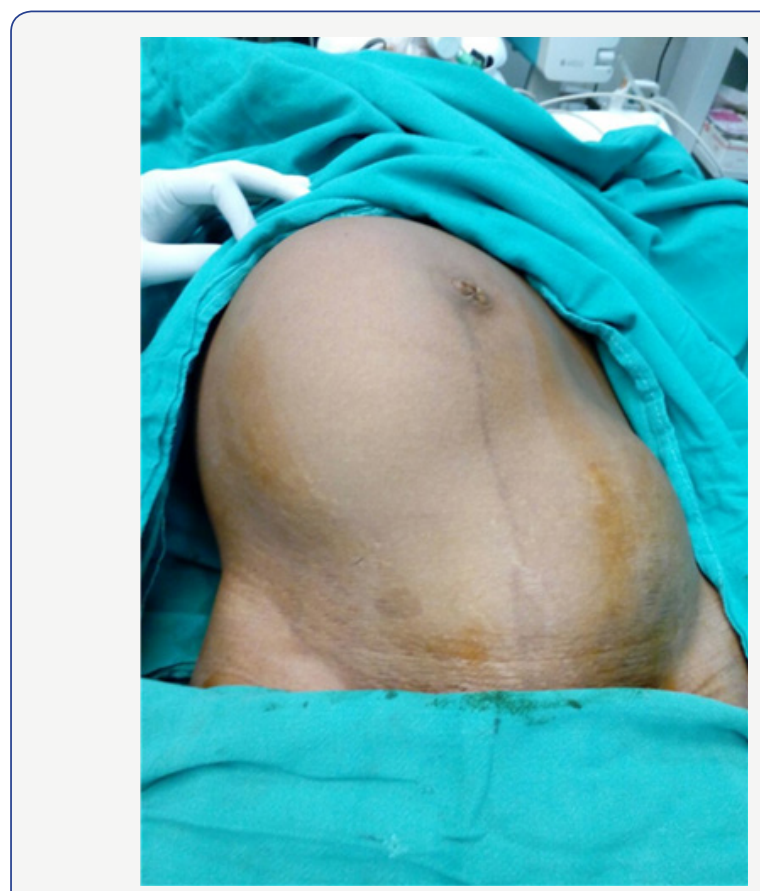

Figure 1: Distended abdomen with two separate lumps.

On sonography 16 weeks intrauterine live pregnancy with large $18 \times 20 \mathrm{~cm}$ size solid cystic adnexal mass was diagnosed. There was no associated ascitis or other pathology detected.

Haematological investigations were found to be within normal limits. Her CA-125 was 90 m IU which was minimally raised. As she was already 16 wks pregnant decision for exploratory laparotomy with conservative surgery was taken. Abdomen was opened by midline infraumblical incision, no 
free fluid was found in peritoneal cavity, left sided twisted ovarian tumour of about $20 \times 16 \mathrm{~cm}$, along with gravid uterus of 16 wks, was found. Surface was smooth; there were no adhesions (Figure 2). Peritoneal washings and omental biopsy were taken. Left sided cystectomy with salpingo oophrectomy was done. Right sided tube and ovary seems to be normal. On palpation there was no other pathology detected. Tissue sent for histopathological examination. Tocolytics were given to prevent uterine contractions and miscarriage.

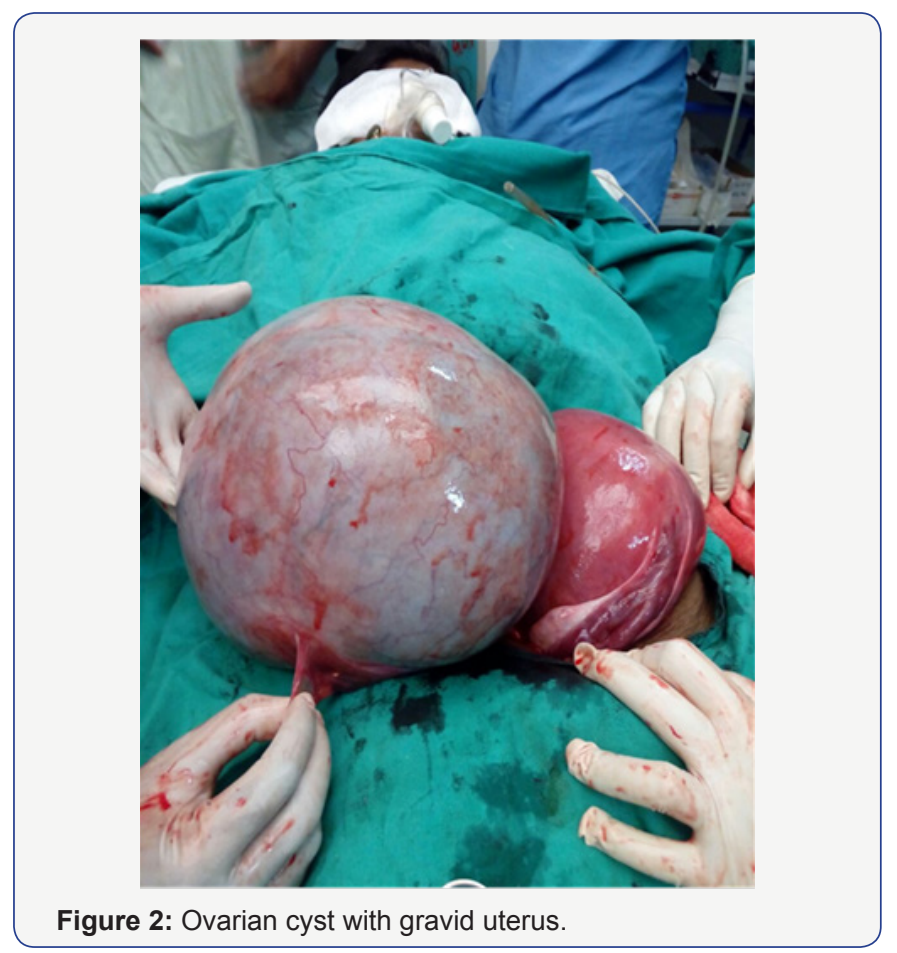

Histology reports turned out to be malignant mutinous cyst adeno carcinoma which was confirmed by IHC (immuno histo chemistry) test also. According to FIGO staging she belongs to stage-1a of ovarian carcinoma with pregnancy (Figure 3).

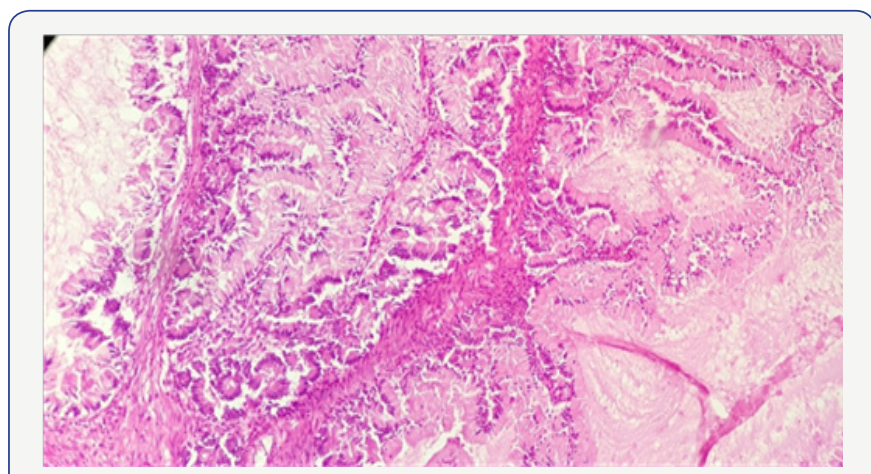

Figure 3: Stage -1 borderline mucinous cystadenocarcinoma.

Post operative period was uneventful. As she was diagnosed as stage- 1 borderline mucinous cystadenocarcinoma, decision to continue the pregnancy and follow up of patient was taken. She is now 36 wks pregnant without any maternal or fetal complications.
There is limited experience of chemotherapy during pregnancy so we decided to go for chemotherapy if required after delivery of baby.

\section{Discussion}

Fewer than $20 \%$ of epithelial ovarian cancers occur in premenopausal women. However, now ultrasound monitoring is routinely used during pregnancy, adnexal mass findings in pregnant women are relatively common [4]. The majority of ovarian cancers associated with pregnancy are diagnosed at an early stage, when disease is still confined to the ovary [5].

As the incidence of invasive cancers and borderline ovarian tumours diagnosed during pregnancy is low, treatment strategies should ideally be discussed and structured during a "multidisciplinary meeting" involving specialists [6]. Pregnant women with ovarian malignancy should be treated in the same way as nonpregnant women [7]. The second trimester is generally considered as the best time for surgical intervention because the risk of miscarriage is lower. Chemotherapy is contraindicated during the first trimester of pregnancy because of the high rate of abortion and abnormal fetal development [8]. It is not the case during the second or third trimester, but the choice of couple must be considered [4]. Pregnant women in advanced stage of ovarian cancer seems to have poor prognosis.

The optimal surgery for staging ovarian cancer includes a bilateral salpingo-oophorectomy, total hysterectomy, pelvic and para-aortic lymphadenectomy, and omentectomy. An analysis of studies of the medical and surgical management of ovarian carcinoma during pregnancy showed that the primary surgery at diagnosis consisted of an ovarian cystectomy, unilateral salpingo-oophorectomy (USO) only, USO plus multiple biopsies or USO plus more radical surgery as infracolic omentectomy, appendectomy, peritoneal biopsies, and even pelvic and paraaortic lymphadenectomy [9].

In case of suspected low malignant potential ovarian mass on laparotomy, if facility of frozen section is not available as in our case, treatment can be conservative by adenexectomy and peritoneal cytology and exploration with biopsies. The treatment should be performed without rupture by a surgeon/anaesthetist team trained to such oncologic surgical procedure in pregnant patients. A super conservative treatment (cystectomy alone) should only be indicated in a patient with one ovary or with a bilateral borderline tumour. If this borderline tumour is revealed by the histology of a surgical specimen as in our case, it seems reasonable, considering the good prognosis of these tumours to defer surgical treatment until after delivery. Surgical staging should be completed 3 to 6 weeks after delivery along with or without chemotherapy [6].

\section{Conclusion}

In spite of a lot of advancement in medical sciences few rural areas are even today suffering from lack of basic health facilities need consideration. 


\section{References}

1. Roy P, Biswas B, Thomas S, Kumar RM, Jose R (2014) Epithelial Ovarian Cancer in Pregnancy: Report of Two Cases. International Journal of Scientific Study 2(7).

2. Ueda M, Ueki M (1996) Ovarian tumors associated with pregnancy. Int J Gynaecol Obstet 55(1): 59-65.

3. Zhao XY, Huang HF, Lian LJ, Lang JH (2006) Ovarian cancer in pregnancy: A clinicopathologic analysis of 22 cases and review of the literature. Int J Gynecol Cancer 16(1): 8-15.

4. Nadereh B, Mojgan KZ, Mitra MG, Fatemeh GAM, Fahimeh G (2008) Ovarian carcinoma associated with pregnancy: A clinicopathologic analysis of 23 cases and review of the literature. BMC Pregnancy Childbirth 8: 3 .
5. Zanotti KS, Belinson JL, Kennedy AW (2000) Treatment of gynecologic cancers in pregnancy. Semin Oncol 27(6): 686-698.

6. Morice $P$, lhommé $C$, lecuru $F$, Canis $M$, levèque J, et al. (2008) Guidelines for the management of ovarian cancer during pregnancy. Department of gynaecology and obstetrics.

7. Gershenson DM (1994) Management of early ovarian cancer: germ cell and sex cord-stromal tumors. Gynecol Oncol 55(3 Pt 2): S62-S72.

8. Karlen JR, Akbari A, Cook WA (1979) Dysgerminoma associated with pregnancy. Obstet Gynecol 53(3): 330-335.

9. Aykut B, Ilker A, Figen B, Muge H, Mehmet I H, et al. (2011) Ovarian cancer during pregnancy. JPMA 61(9): 914-916.

\section{Your next submission with Juniper Publishers will reach you the below assets}

- Quality Editorial service

- Swift Peer Review

- Reprints availability

- E-prints Service

- Manuscript Podcast for convenient understanding

- Global attainment for your research

- Manuscript accessibility in different formats

( Pdf, E-pub, Full Text, Audio)

- Unceasing customer service

Track the below URL for one-step submission https://juniperpublishers.com/online-submission.php 